\title{
BASIS FOR A NEW THEORY OF DRAWING FRAMEWORK FROM TRADITIONAL HANDMADE TO MODERN VIRTUAL SIMULATION
}

\author{
Mauricio NOVOA \\ Western Sydney University, Australia
}

\begin{abstract}
This article builds on previous work (2019 E\&PDE) that proposed the need for a new theory for drawing. Now, there are new platforms for delivery and technology that test the traditional notion of good drawing. Also, there are drawings that do not adhere to traditional Western Renaissance or Victorian aesthetics. Yet, they are good drawings because their rich communication. The methods of this article work at three levels. First, a selection of key typologies on good drawing for cognition, communication and design in the last thirty years. Second, a historical review. Third, a user experience and participatory action research model that trials the gaps and differences between traditional and new forms of drawing skills. This paper outcomes offer a new set of parameters for good drawing and a standpoint to frame findings from the congruence between critical pedagogy, cognitive sciences and semiotics. Particularly, the perspective coming from a new wave of constructionism, critical making, enactivism, and social, interpretative and visual semiotics. This is the base for a work-in-progress framework draft for discussion that balances diverse typologies cited here. Ultimately, the paper proposes that modern manifestations of good drawing works best as a collection of open works, based on a shared metastructure, that connect creators and their audiences through contextualised and clear codes that assist their reading.
\end{abstract}

Keywords: Drawing, enactivism, interpretative semiotics, social semiotics, visual semiotics

\section{INTRODUCTION}

The good drawing concept goes back to Titian when he said, "it is not bright colours but good drawing that makes figures beautiful". Artists and architects used it for visual research, realistic propaganda and scientific representation. Drawing was freed up from representational limitations with the start of photography (Greek photo: light; graphe: drawing, writing). Technology also enabled drawing as a presentative tool in-between two ends of the communication spectrum. Artists showed their emotions and views in ways that neither painting nor photography could do. Exemplary, Cezanne (1839-1906), Matisse (1869-1954) and Picasso (1881-1973) transformed the good drawing from realism to impressionism, cubism and expressionism. Dix (1891-1969), Beckman (1884-1950) and Grosz (18931959) depicted how the abnormal became a new normal when social parameters were transgressed in Europe. Grosz said, "my drawings expressed my despair, hate and disillusionment". Whereas, architects and designers also departed from traditional forms of crafting and representation. But for them, good drawing was about ideation, illustration, and greatly, engineering detail to support industrialization at a time of rapid social changes, and advances in science and technology. Many of them did functionalist drawings with a modernist God talking from the top of the hill view that treated people as consumers.

\section{PROBlem STATEMENT}

Today, drawing has a wide scope of applications from two-dimensional (2D) to three-dimensional (3D) computer aided design (CAD), augmented (AR), virtual reality (VR) and immersive and distributed environments. Scholars have tried to categorise drawing types for education and the profession according to skill and application (e.g. personal, shared, persuasive, handover sketch), creativity (e.g. imitation, self-expression), capabilities, didactics, materials, purpose, representation (e.g. interpretation of brief, epiphany, technical layout) and techniques. Yet, there is still lack of a defining inclusive framework for drawing skills for today and tomorrow's communication and technology. 


\section{METHODS}

The methods in this paper comprise three levels. First, a review of key drawing classifications. Second, a historical review of drawing skills and techniques. Third, the trial of a user experience and participatory action research model that investigates the relationship between the drawer, his/her audience and their environment. These methods are presented for discussion with the intention to learn from the conference feedback and to develop them onto a robust design research and an extended journal paper later.

\section{RESULTS}

\subsection{Key studies}

Classical antiquity and the Renaissance resurged with the École des Beaux-Arts. Students learned by copying and imitating the great masters from art and architecture. Following, they developed quick conceptual sketches and highly finished perspective drawings. The academy proposed that students would become creative after mastering techniques. Research conducted by Corremans et al $[1,2]$ found that this approach is still in use. It appears that students who sketch better seem more likely to score higher in product design projects. Yet, the same research noted that design learning is complex, and it is simplistic to think that quality and creativity will improve if design schools invest more resources and time in hand-drawing courses alone. Many professionals are also critical about teaching students by reproduction based on dated views of industry standards. The renowned designer Gadi Amit said that design schools ought to redefine their content and purpose as per today's parameters of creativity and innovation. Most graduates' portfolios show drawings, 3D CAD and renderings that lack cultural, aesthetic and form intelligence insights. Consequentially, they fail to prove knowledge of real design process and capacity to integrate seamlessly all levels of creativity.

Several researchers have again made drawing their focus because of its role in architecture, art and design. Among them (because of lack of space), the Second Conference on Visual and Spatial Reasoning in Design at MIT, the Thinking through Drawing Symposiums by 12345 Draw that also organises seminars and courses since 2011, the Drawing Research Network hosted by TRACEY at Loughborough University that supports the value of drawing in education and the profession. From the latter university, Pei, Campbell and Evans [3] developed a taxonomy for visual design representations (VDR) that includes drawing within four measurements (orthogonality, spanning, completeness, usability) and groups drawings either as personal, shared, persuasive and handover sketches. They developed their VDR taxonomy from Schenk's [4] thirty years research. However, she grouped drawings based on their use, types and capability. Recently, Hoftijzer et al [5] produced a new typology that considered previous approaches and proposed that all design drawings are about communication and must include 3D information, visualisation, representation, layout, varying levels of specification and rendering. Drawings were grouped into the stages of interpretation, epiphany and technical layout.

\subsection{Historical review}

The dimensionality, platforms and tools for drawing have gradually changed until now. Aptly, its user experience needs to be redefined to benefit the producer and the audience that interprets it. However, many practitioners assume everything is as before. Inspection of local traditional educations confirmed findings by Corremans et al [7,8]. Often, design students learned by copy and templates (colouring between the lines view) from books on product design illustration and the Renaissance. It became clear that drawing by imitation does not address critical circumstances, know-how and vision differences among an original drawing and its copy, old and modern ways to do it. Exemplary in the Renaissance, drawing was the closest skill to design. They shared their original Latin root (designāre: to design, draw, mark a sign). Drawing was the means to project intellectual ideals and the structuring base for fine arts, architecture, engineering and planning. Yet, materials were expensive and took time to prepare. The drawer negotiated a hard interaction between him/her, a model (live or dead) and rough supplies (e.g. chalk, charcoal, ink from iron salts and tannic acid, quills from goose's feathers, paper or parchment of untanned animal skin). Precise drawings were done with a metal point on paper coated with ground bone. Materials allowed one chance to make it right. Drawing was a deliberate act of mental and physical experience that was resolved simultaneously by the brain, the muscles and the hand.

Today, there is a paradox created by obstacles of cost, know-how, technology and time. In general, learners lack the self-assurance of old times when artists and architects confidently made new things thanks to their ongoing dialogue with valued materials, objects and drawings that were artefacts (Latin 
arte: skill, factum: human made) of language. Their work showed the conviction of belonging to an intellectual revolution. Our students also appear detached from critical user experience. Transferring skill by imitation, inexpensive materials, and the repetitive use of erasers, rulers and the Undo command in computers seem to hinder their capacity for self-actualisation (fulfilment and realisation of talent and potential). Cost and short length of courses also make new technology inaccessible. Technology also has limitations that make it too abstract for naïve sketchers as well (e.g. feedback loop mechanisms in higher forms of 3D VR and immersive environments).

Rapid changes have disrupted opportunities to reframe the drawing user experience. Literature review tells that there is scarce research on how new technology affects traditional drawing skills and whether new ones are needed. Shifting educational strategies have also derailed its education. Two decades ago, Evatt and Brodhurst (2002) indicated to an increased focus on drafting. While there was lack of proper 3D CAD tuition and poorer basic freehand drawing knowledge and visualisation ability in higher education. They were concerned because "the computer is not and will never be superior to all the other tools at every stage of product development" [6]. Later, Evatt (2006) noted that the ICT revolution did not deliver on a promise of more time for drawing tuition. He trepidated about the increase of 3D CAD training at the cost of reduced learning on observation, drawing and design skills that are essential for competent designers [7]. In the last decade, technology has come closer to making the computing experience as easy as working with traditional pencil and paper. It is said that digital tablets, AR and VR will extend drawing onto mobile, immersive and distributed environments.

\subsection{User experience}

A small participatory action research tested whether user experience changes among those technologies. It was not encompassing but still delivered important findings that are intended to be measured on a larger experiment and project later. Its overarching focus compared cognitive load and Guiard's model of bimanual skill (preferred and non-preferred hand). It also shared elements with Gutenberg Diagrams (2D reading gravity and user behaviour), Fitts Law (3D target size and distance effects on acquisition time to predict use in digital environments), and performance metrics (e.g. completion time, accuracy). These methods cannot separately assess if there are differences among old and new forms of practice since their measurement mechanisms are commonly about following, pointing and clicking, tracing, tracking (e.g. gaze and hand between a canvas and a model) and recreation of templates. Understandably, the main areas considered in this research at this point were the difficulty of tasks that correlate with learning time, fatigue and stress, right and wrong effort, and inability to timeshare. Hence, four variables were chosen with a rating scale from 0 (no action) to 5 (accomplished task):

- $\quad$ Learning curve: Reaching from naïve to expert

- $\quad$ Error susceptibility: Ranging from hesitation to random, direct and firm movements

- Orientation: As the lead driver to achieve navigation, organisation and position of work

- Team and time sharing: Either among a group or because of bimanual tasks

Two males and two females (equal blend of naïve and amateur traditional sketchers) with a mean age of $22(S D=2.7)$, and one expert for benchmarking, were recruited for three two hour sessions to assess freehand drawing across several platforms (pencil and paper, Autodesk Sketchbook on an iPad using a stylus, 2D Sketch.io Mobile on a multitouch tabletop using fingers, VR Tilt Brush and Gravity Sketch using Oculus Rift $\mathrm{S}$ headset and touch controllers). The expert and the researcher were the two controls in the test. Initially, the participants were introduced to the different devices and features. First, they were shown exemplars once and asked not to copy them. Instead, they drew an object from their mind (a hand-drill or a car, an anthropomorphic figure and a visualisation map of the process) individually or as a group (depending on task), with limited chances for erasing, deleting or use of the Undo command. Activities swapped every twenty minutes and were checked at fifteen minutes intervals. In the second session, they created the objects again with less chances for undo. A third session repeated the activity to check for changes and/or confirm progress. The combined results are as follow (Figure 1).

The experiment clearly showed a clash between behaviourism and cognitivism. The same activity (drawing) tested pre-fixed repertoire of behavioural responses when the drawing support and technology changed from horizontal to vertical position, individual to group interaction, 2D to 3D, Polygonal and NURBS VR immersive environments. Participants had to redefine circumstances to actively construct new ways of learning and drawing since they could not copy models and did not have much precedent to work with when using newer technologies (e.g. VR immersive environment and software was new to them). On observation and based on free comments contributed, participants made learning effective 
every time they successfully disconnected from traditional drawing parameters (e.g. 2D, pen and paper conventions) and relinked their diverse challenges and drawings to somehow similar relations between drawer, context and audience/reader. In the participatory action research process, participants started to find a common underlying meta-structure that enable them to still call their work a good drawing regardless of its appearance. The most successful pieces were open works that presented their own semiotic (Greek sēmeioun: sign and symbol interpretation regarding function and origin) clues (coding) for interpretation. These were idiosyncratic $2 \mathrm{D}$ and $3 \mathrm{D}$ visual literacy parameters that counterparts were capable to read (e.g. top-bottom gravity, consistency, proportion).
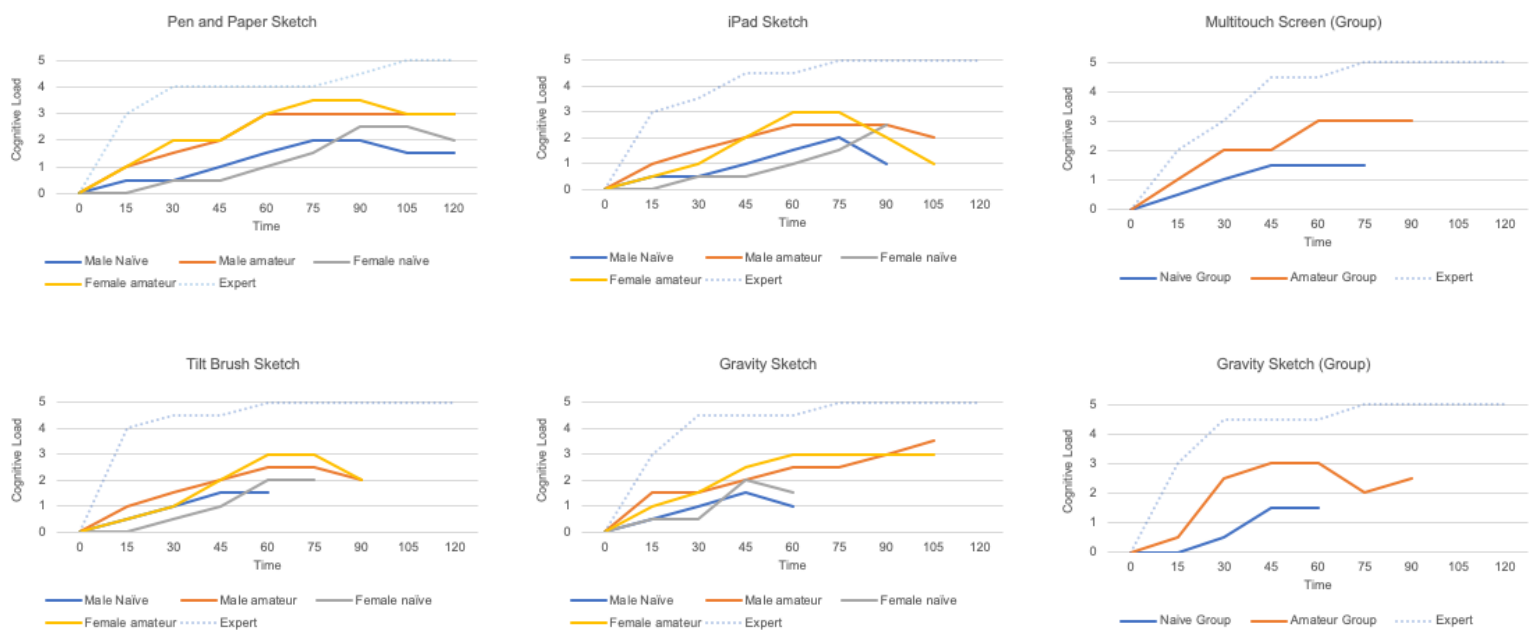

Figure 1. Cognitive load charts for different drawing user experiences from $2 D$ (individual pen and paper and iPad, and group multitouch screen) and 3D VR (Tilt Brush, Gravity Sketch, and group Gravity Sketch co-creation) that combine learning curve, error susceptibility, orientation and timeshare variables

Charts above and comments showed that naïve participants were more prone to fatigue, to jump from task to task, and to stop before the session was over. Participants hesitated and acted randomly before gaining some orientation that allowed to organise their work. The smooth touchscreens surface, the use of a stylus, and a finger as stylus, did not give enough feedback to assist going further compared to traditional pencils and paper. The multitouch tabletop group experience broke away from the Gutenberg model (e.g. vertical, horizontal, left, right) and participants felt pushed to draw from the edges to the centre either like the work by Australian aboriginal artists or quilting instead of drawing. It meant that $3 \mathrm{D}$ volumes and perspective were not easy to do while visualisation maps were simpler to achieve. Often in group work, one member tried to take control indistinctly of 2D and 3D VR environments.

Bimanual timesharing surprised the participants. They realised how much the non-preferred hand had an active role in the success of a drawing by setting the spatial frame of reference for the fine movements of the preferred hand across the different tests. They specially noted a difference between VR Polygonal and NURBS applications. Naïve participants were overwhelmed by Tilt Brush's numerous features. Thinking with the pen, as said colloquially, was not straight forward as dynamic brushes distracted when trying to structure shapes (e.g. fire, embers, electricity). Naïve and amateurs said it was too freeform and felt Gravity Sketch was easier to form objects. Regardless, both applications forced them to rethink their drawing skills since VR asked for full body commitment to enact their work. The experience was closer to sculpting and animation because of the need to resolve problems as "real" 3D large scale volumes that they were not trained for (e.g. depth, distance and time relations). The user experience also had gaps relating to dexterity and fine motor skills. Touch controllers were analogue joysticks that were represented virtually as a hand and a pointing finger (when drawing). Further, haptic feedback mechanisms that induce physical feelings relating to materiality, gravity and texture, were missing. These issues were too abstract for the naïve to interpret and verbalise. Instead, they often were confused and abandoned a task. More skilled sketchers replaced haptics by provoking an approximation by visual perception (e.g. sharp versus fluid lines, closed versus open shapes, colour). 


\section{DISCUSSION}

\subsection{Evaluation of results}

The key typology studies, the historical review and the user experience/participatory action research brought to surface a new understanding for participants. It differed from the conventional good drawing taught in academia. The interaction between the drawer, the other and the environment became pivotal regardless of the support used. Thus, participants noted that it was easier to sort out skill and technology problems when considering drawing as multimodal fact of language that required capacity for translation between platforms. Findings aligned with constructionism as the belief that people learn best with a peer reviewed and shared investigation of making tangible things [8], critical making that bridges the gap amid physical creativity and conceptual exploration via hands-on work and digital technologies, embodied cognition that requires the coordination and involvement of an entire person; not just a brain/hand function issue [9], enactivism that means that cognition arises through active interaction between a sketcher, his/her audience, the drawing and their environment [10], social semiotics that tries to explain meaning-making as a social practice [11], interpretative semiotics since drawing depends on translation and interpretation [12], and visual semiotics that analyses the way that visual images (e.g. drawing, picture, text) communicate a message in terms of signs and patterns of symbolism [13].

\subsection{Work-in-progress framework}

This preliminary research shows that drawing and its skills are going through a change like the larger scale transformation in design thinking, process and manufacturing. Hence, what is a good drawing should be redefined together with the types of marking a sign that constitute it and is taught in design education today. Old divisions amid drawing for ideation, design, prototyping, 3D CAD specification, 3D Polygonal and Parametric construction and manufacturing are blurring. Still, this is not new. At the cutting edge, Ford Motor Company set up its C3P 3D VR project back in 1995 and its VR prototyping lab (Ford Immersive Vehicle Environment) in 1999. Its first digitally developed Mondeo car launched in 2001. Its Studio 2000X works with Tilt Brush for design ideation and pre-development since 2016. The company joined Gravity Sketch for distributed co-design in a global 3D VR space that improves decision-making and assembly. Ford is also developing VR manufacturing to optimise fabrication, machining, workflow and to control robotic manufacturing. Graduates need that know-how since the digital and physical divide closing. The technology is already at reach for education. Software, like Shapr3D and Gravity Sketch, offer end-to-end pipelines that merge sketching, CAD design, co-creation and 3D printing. Yet, a critical challenge is to redefine drawing and its skills within the modern digitalphysical realm, while, the latter is now transitioning to the new ground of human-cyber-physical systems based on communication, control and intelligent computing (e.g. generative design). Suitably, a new type of elastic framework is needed to accommodate past, current and future drawing redefinitions and their skillsets (Figure 2).

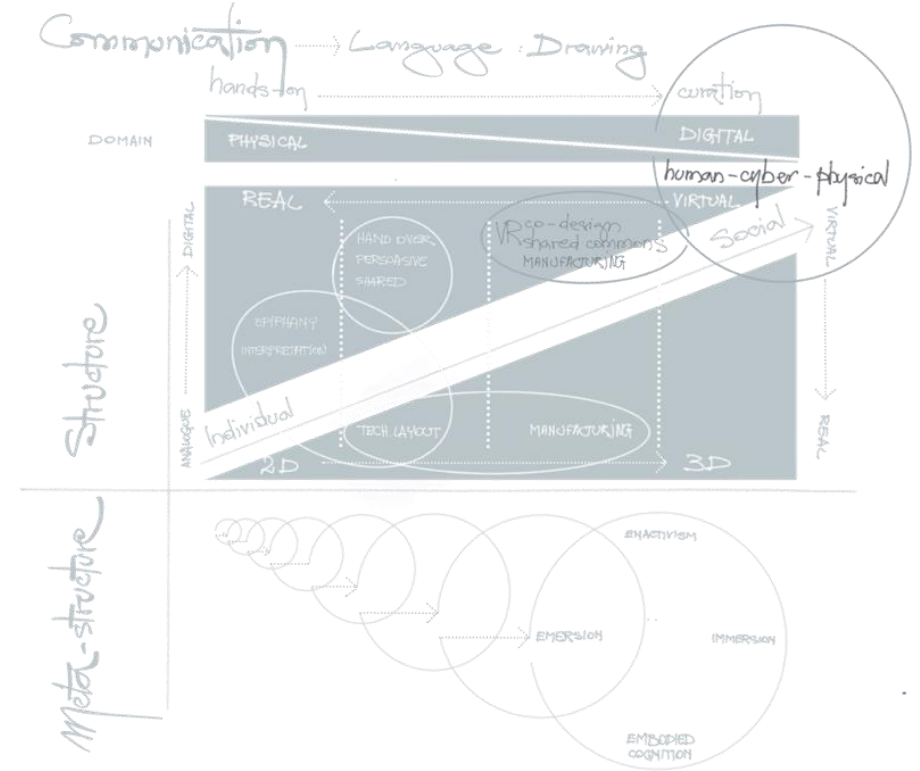

Figure 2. Drawing new environment framework (work in progress) 
This in progress multimodal framework addresses existing experience, skills and their likely variations by relinking prior models (as per function, intention, ownership or representation type) with a key vision of critical cognition and social interaction. It allows for a spectrum ranging from hands-on to curatorial and artificial definitions of practice; the more analogue reality gives space to algorithmic (coded process) and artificial (machine learning) intelligence. The flexible scaffolding relies on an underlying metastructure foundation for all social communication and meaning making, including drawing and design. Essential to it is a four stages iterative process for cognition and creativity. First, emersion (Latin emerso: to emerge) of individual ideas. Second, enactivism of personal experience with active interaction with others, the environment and the means that mediates communication with them. Third, immersion (Latin immergere: to dip in) that absorbs individuals and groups into representing an idea and its reality and presenting a new idea and its new reality. Fourth, embodied cognition as intellectual and whole-body participation to generate, communicate and adopt meaning and innovation.

\section{CONCLUSIONS}

This article focused on drawing since it is the closest skill to design. Technology has progressed greatly but drawing education has not kept the same pace. Different typologies label drawing skills by function, intention, ownership or representation type. Yet, the dare is out about a new definition for good drawing, its competencies and platforms that can make it essential again for communication and innovation. An initial experiment unearthed shortcomings and opportunities to consider. A preliminary framework proposed a multimodal perspective based on critical cognition, social interaction, and meaning making. As per findings, there are three tasks to work on. First, a broad and in-depth research to reveal evidence for verification. Second, an elastic definition for good drawing flexible enough to allow translation and interpretation regardless of the platform used. Third, to articulate its taxonomy of skills and attributes. The likely bonus will be to validate the drawing practice for the current digital-physical domain and the capability to transition it for upcoming dimensions, such as, the one of human-cyber-physical systems.

\section{REFERENCES}

[1] Corremans, J.A. and Coppieters, W., Does the imitation of the sketch style of good industrial designers influence students' drawing skills? . In DS 88: Proceedings of the 19th International Conference on Engineering and Product Design Education (E\&PDE17), Building Community: Design Education for a Sustainable Future, Oslo, Norway, 7 \& 8 September 2017. 2017.

[2] Corremans, J.A., Vaes, K.R. and Coppieters, W., Do better sketchers become better product designers? In DS 92: Proceedings of the DESIGN 2018 15th International Design Conference. 2018.

[3] Pei, E., Campbell, I. and Evans, M., A taxonomic classification of visual design representations used by industrial designers and engineering designers. The Design Journal, 2011. 14(1): p. 64-91.

[4] Schenk, P. Developing a taxonomy on drawing for design. International Association of Societies of Design Research, 2007: p. 1-15.

[5] Hoftijzer, J., et al. A typology of design sketches, defined by communication factors; the case study of the Thule Yepp Nexxt child bike seat. In DS 93: Proceedings of the 20th International Conference on Engineering and Product Design Education (E\&PDE 2018), Dyson School of Engineering, Imperial College, London. 6th-7th September 2018. 2018.

[6] Evatt, M.A.C. and Brodhurst, E.K., Sharing Experience in Engineering Design (SEED 2002). 2002: Wiley.

[7] Evatt, M.A.C. Drawing conclusions. In DS 38: Proceedings of E\&DPE 2006, the $8^{\text {th }}$ International Conference on Engineering and Product Design Education, Salzburg, Austria, 07.-08.09. 2006. 2006.

[8] Harel, I.E. and Papert, S.E., Constructionism. 1991: Ablex Publishing.

[9] Maturana Romecín, H. and Varela, F.J., El árbol del conocimiento: las bases biológicas del entendimiento humano. 2009: Editorial Universitaria.

[10] Baerveldt, C. and Verheggen, T., Enactivism and the experiential reality of culture: Rethinking the epistemological basis of cultural psychology. Culture \& Psychology, 1999. 5(2): p. 183-206.

[11] Hodge, B., et al. Social semiotics. 1988: Cornell University Press.

[12] Eco, U. A theory of semiotics Bloomington. Indiana: Indiana, 1979.

[13] Kress, G.R. and Van Leeuwen, T., Reading images: The grammar of visual design. 1996: Psychology Press. 